Анастасия Гулина

Люблин

\title{
Национальная самоидентификация в современной русскоязычной драматургии Беларуси и Украины
}

Современный человек живет преимущественно в поликультурной реальности, с чем напрямую связано разнообразие форм его культурной жизнедеятельности. Формируясь в рамках культуры своей страны, испытывая прямое воздействие культуры той социальной группы, того народа, к которой он принадлежит, современный человек связан и с культурой других народов, других людей, более широкой, всеобщей системой связей и зависимостей.

Всемерно расширяются и усложняются культурные контакты между народами и различными регионами мира. Все более возрастает значение обмена между их материальными и духовными ценностями. Растет потребность личности в освоении всего культурного богатства человечества, в более глубоком и всестороннем приобщении к культурным достижениям разных стран и народов.

Все эти процессы наиболее динамично развиваются в современном мультикультурном информационном пространстве. Именно поэтому происходит актуализация, а иногда и обострение тех социальных проблем, которые вне его не столь очевидны. Одной из них является проблема формирования и непосредственного сохранения национальной идентичности личности в условиях поликультурности.

В Украине и Беларуси, как и в других бывших советских республиках, проблема идентификации особенно заострена. Переписывается история, ведутся постоянные споры о том, кого из исторических деятелей правильно считать героями, а кого - предать анафеме. 
Также в обеих республиках проблема идентичности напрямую связана с двуязычием населения. По данным опросов общественного мнения, в Беларуси около 90 процентов населения предпочитает русский язык национальному, а в Украине количество русскоговорящих варьируется от 35 до 50 процентов.

Учитывая эти данные, неудивительно, что общей особенностью современной драматургии в Беларуси и Украине является наличие значительного числа авторов, пишущих на русском языке (Елена Попова, Андрей Курейчик, Юлия Чернявская, Николай Рудковский, Павел Пряжко, Константин Стешик, Дмитрий Богославский - в Беларуси, Анатолий Крым, Мария Ладо, Клим, Анна Яблонская, Александр Мардань, Наталья Ворожбит, Максим Курочкин - в Украине).

Пьесы этих авторов известны не только на родине, но и в России, попытки определения их принадлежности к той или иной национальной литературе вызывают большие трудности у литературных критиков и театроведов.

Некоторые исследователи отказывают рускоязычным авторам в праве называться белорусскими или украинскими писателями и на основе языкового критерия категорично причисляют их к русской литературе. Другие критики, на основе тематики произведений и ментальности героев, относят рускоязычных авторов к белорусской или украинской литературам, находя в их пьесах существенные отличия от произведений русских коллег.

По мнению П. С. Гуревича, идентификация является глубинной человеческой потребностью ${ }^{1}$. Как же позиционируют себя сами драматурги в своих произведениях?

\section{Белорусские мечтания о светлом будущем}

Пьесы Николая Халезина «Поколение Jeans. Ода новой генераиии» и «Небо» Андрея Курейчика имеют много общих черт.

Обе пьесы, по сути, представляют собой исповедальный монолог главного героя (прием, сразу заставляющий вспомнить моно-пьесы Евгения Гришковца), повествующий о «неком» взрослении, самоосознании и попытке понять свое место в современной реальности.

По первым страницам пьесы героя Николая Халезина никак нельзя назвать белорусом. Очень большой процент бывших советских граж-

1 П. С. Гуревич, Культурология, Москва 2007, с. 280. 
дан могли бы также рассказать о том, как сложно было доставать импортные пластинки, как нужно было хранить полиэтиленовые пакеты и правильно носить джинсы.

Гражданская позиция рассказчика также вызывает сомнения. Еще учась в школе, он мечтает стать «фарцовщиком»²: Школа внезапно закончилась, и мечта стала явью.... А первое столкновение с бдительными следователями рассматривается героем не как нарушение его гражданских прав, а прежде всего как неприятность, чреватая финансовыми убытками: Тут твое лицо должно вспьхнуть краской праведного гнева, означающего, что судьба странь волнует тебя не меньше, чем вопрос «вернут ли эти говнюки твой товар? ${ }^{3}$.

Тем не менее, джинсы для героя - это не только источник благополучия, но и идеология. Через форму одежды он идентифицирует себя и свое поколение:

Джинсы были для нас символом свободы - свободы доступной. K тому же, они были кусочком Америки или Британии - недоступных нам центров мира настоящей музыки и настоящего кино. Настоящих! Не наших вечных подделок «под...». Не кино про Америку, снятое в Прибалтике... На-сто-я-щих!!! Знаете, для чего мы фарцевали джинсами и пластинками? Для чего нам нужны были деньги? (Пауза) Чтобы покупать пластинки и джинсы ${ }^{4}$.

Сам термин «поколение джинс», который стал названием пьесы, был придуман не Николаем Халезиным, а участниками политической, антиправительской демонстрации, которая состоялась на главной площади Минска 16 сентября 2005 года, когда после изъятия милицией у демонстрантов бело-красно-белого флага, их новым флагом стал джинсовый.

Как замечает автор монолога, в этой демонстрации принимали участие прежде всего молодые люди, что свидетельствует о том, что будущее белорусского народа им не безразлично, что эти люди заинтересованы в креативном действии и, что они нуждаются в изменении политической системы. Инициаторами и организаторами этой демонстрации оказались талантливые, профессионально состоявшиеся рок-звезды, а ее главной причиной было ограничение свободы, прежде всего, современного творчества.

2 Н. Халезин, Поколение Jeans, режим доступа: http://www.theatre-library.ru/ authors/h/halezin, дата доступа: 12.10.2013.

3 Там же.

4 Там же. 
Именно с этим поколением идентифицирует себя рассказчик. Но при этом герой ни разу не называет ни себя, ни отдельных представителей поколения, о котором рассказывает, белорусами.

Когда у демонстрантов отнимают национальный бело-красно-белый флаг, они, даже не задумываясь, заменяют его джинсовым, который у них ассоциируется с Западом. Прежде всего они борются за свободу слова, за свободу творчества, а не за белорусские символы или белорусское искусство. Это подтверждается британской и американской рок- и джаз-музыкой, запускаемой ди-джеем на протяжении рассказа героя (в пьесе Стоппарда «Рок-н-ролл» рок-композиции также являются необходимым фоном для событий).

С другой стороны, герой пьесы, как и представители «поколения джинс», не покидает страну, в которой родился, не уезжает жить за границу, а выбирает более сложный путь - он остается в родном Минске и, несмотря на реальную опасность, предпринимает разные действия, которые, по его мнению, могут привести к свержению режима в Беларуси, к изменению закона, а в конечном счете, к лучшей жизни граждан этой страны.

Он хочет жить в своей стране. Он борется за то, чтобы его страна стала другой. И об этой другой стране он говорит в финале своего монолога. В этом светлом будущем, по мнению героя, он и другие «джинс» смогут играть свою музыку, открывать университеты, по-прежнему носить джинсы и быть по-настоящему свободными.

Другими словами, возвращаясь к цитате П. С. Гуревича ${ }^{5}$, peaлизовывать базовые потребности личности: в общении, в творчестве, в стремлении к познанию и т.д., на основе которых они наконец смогут признать себя свободными гражданами своей страны.

«Небо» Андрея Курейчика, как и «Поколение Jeans», носит исповедальный и автобиографический характер. Историю создания небольшой группой молодых людей арт-клуба в Минске сам автор пьесы представляет как: moja próba powiedzenia prawdy o Białorusi. Moja próba znalezienia nowego, wspótczesnego, białoruskiego bohatera. Aktywnego. Uczciwego. Bezkompromisowego. A może odnalezienia siebie $w$ dzisiejszym społeczeństwie białoruskim ${ }^{6}$.

5 П. С. Гуревич, Культурология, с. 280.

6 A. Kurejczyk, Białoruskie wysepki wolności, tłum. P. Mitzner, "Dialog", Warszawa 2005, nr 12, s. 69. 
Впрочем, те общественные явления, что затрагиваются в пьесе (кумовство, коррупция, беспредел чиновников, бюрократизм) Андреем Курейчиком, характерны не только для белорусской действительности.

Ситуация, когда И вот, после почти трёх месячев адовых мук, потеряв сон, вес, аппетит и чувство собственного достоинства, c папкой весом один килограмм семьсот шестьдесят грамм, испешрённой подписями и печатями бумаги, я снова вернулся $к$ Сергею Кузьмичу, чтобь поставить последнюю подпись и получить заветное разрешение... ${ }^{7}$ могла бы случится и в России, и в Украине, и во многих других советских республиках.

Дискуссии героев о политической ситуации в стране также являются «универсальными» для многих постсоветских республик, достаточно лишь сменить (или убрать) фамилию президента:

«Диктатура - это режим, при котором или всё время выигрывают, или всё время проигрывают. Так вот мы из первой категории», «У нас ведь всегда так: сначала нарушаешь права, затем занимаешься проблемами их защиты. Впрочем, иногда и наоборот», «А я не хочу делать флюорографию, чтобы учиться в университете. Потому что это маразм, делать флюорографию, чтобы изучать правоведение. А приходится! Маразм - это необходимая составляющая нашей жизни. Все с ней мирятся...», «...в этой стране просто не может быть абсолютно законопослушных людей. Все что-то нарушают. Это рай для прокурора», «Эта страна - зародыш. И люди здесь должны вести себя как зародыши. Присосаться пуповиной к государству и не рыпаться. Умереть не дадут. Вырасти тоже. Зародыши, понимаешь?».

Но при этом для достижения своей цели герои пользуются теми же средствами, против которых так горячо выступали - семейными связями одного из них.

Центральным персонажем пьесы и одновременно рассказчиком, представляющим свою историю, является Никита Андреевич Мицкевич. Имя и фамилия главного героя «Неба»- это одновременно псевдоним автора пьесы. Наиболее полно образ Никиты Мицкевича передают его собственные монологи. У него неслучайное имя. Никита - имя греческого происхождения, которое в переводе на русский язык означает победитель. Мицкевич - это, в свою очередь, известная фамилия, носителем которой был прежде всего Константин Михайлович Мицкевич, известный под псевдонимом Якуб Колас - народный поэт Беларуси,

7 А. Курейчик, Небо, режим доступа: http://www.theatre-library.ru/authors/k/ kureychik, дата доступа: 15.10.2013. 
произведения которого входят в разряд национальной классики. Носителем этой фамилии являлся также называемый польским национальныл бардом Адам Мицкевич, представитель романтизма, неутомимый борец за независимость, самый известный пропагандист польского мессианизма.

Казалось бы, давая герою фамилию выдающихся писателей, автор старается сохранить в пьесе национальный колорит. Но при этом, выбирая название для своего клуба, герои крайне нелицеприятно высказываются о Якубе Коласе:

Оленька. А может быть попробовать что-нибудь белорусское, национальное. Мы же здесь живём...

Федя. «Харошки», «Куток», «Снапок»?

Ваня. Может, просто «Якуб Колас».

Никита. Почему Якуб Колас?

Ваня. Мы его в школе проходили.

Олег. Кошмар.

Ваня. Почему?

Олег. Это просто чудовищно... Он же плохой поэт.

Ваня. А нам говорили хороший. Мы даже наизусть его учили.

Олег. Ну нельзя, нельзя так позориться...8

Как и «поколение джинс» Халезина, герои Курейчика не стремятся к возрождению белорусской культуры и языка, они хотят проводить вечера памяти Джима Моррисона и устраивать концерты альтернативной музыки. Никита Мицкевич, впрочем, предлагает читать поэту Олегу Лунгину в арт-клубе свои стихи (написанные на русском языке), но это начинание так и остается проектом.

Герои «Неба» ровно на год получают желанную свободу, но, несмотря на все возвышенные споры в начале пьесы, используют они ее довольно банально: «тусуясь» в клубе и покуривая марихуану.

Можно с уверенностью сказать, что герои находятся в тупике самоидентификации: они живут в Минске, но выросли они на образцах советской, русской культуры, и сейчас являются поклонниками различных европейских и мировых тенденций моды. Они говорят на русском языке. С детства помнят советские мультфильмы: «Золотую антилопу», «Каштанку», «Карлсона». Они вспоминают персонажей таких произведений русских классиков, как «Идиот», «Преступление и наказание», «Старуха Изергиль». В пьесе «Небо» упоминаются также

8 Там же. 
фамилии советских и русских артистов: актрисы Надежды Васильевны Румянцевой и музыканта Владимира Николаевича Чекасина, а также российские рок-музыканты Гребенщиков, Земфира.

Непримиримым индивидуалистом пытается представить себя Никита Мицкевич. Свою позицию он часто подчеркивает, используя личное местоимение «я» и местоимения «мой», «мое», например: моя история, мое Небо, я во главе, мой праздник, мое заведение. Сам называет себя боссом.

Столкнувшись с произволом власти и отказавшись подчиняться, Никита прежде всего возмущен финансовой составляющей проблемы: Идут они в заднииу. Я не дам им ни копейки. Я не дам им ни копейки моих денег. Это мои деньги! Я их заработал! И я лучше их сожгу, чем отдам им.

Но такая позиция в большей степени является показной: клуб построен на деньги и благодаря связям его друга Бориса, который также контролирует всю финансовую деятельность заведения и договаривается с поставщиком наркотиков, пока Никита упивается мнимой свободой. Да и не стоит забывать, что помещение клуба предоставлено все теми же чиновниками.

Но, тем не менее, именно этот конфликт помогает Никите прийти к тем же принципам, что провозгласило для себя «поколение джинс»: Я не могу это бросить. Я не могу бросить своё Небо. И не хочу убегать! Я хочу бьть свободным здесь, Федя, здесь - в Беларуси, в Минске, на этом грёбаном Партизанском проспекте ${ }^{10}$.

Вопрос о национально-культурной идентичности актуализируется, как правило, при длительном контакте с другой культурой, особенно в моменты конфронтации и противоречий между своим, кажущимся естественным поведением и иным подходом к жизни. В чужеродном окружении осознание своей позиции подвергается постоянному переосмыслению. В такие моменты и начинается процесс самоосознания в сопоставлении себя с другими и поиск ответа на вопрос: что лежит в основе этих противоречий - личное или национальное?

Идентификация героев Халезина и Курейчика начинается именно таким образом - отталкиваясь от противного: от советского прошлого, от «серой» современности, они начинают позиционировать себя в качестве новой категории белорусов с активной творческой и гражданской позицией.

\footnotetext{
9 Там же.

10 Там же.
} 
С точки зрения исследователя Бенедикта Андерсона, главное в национальной идентичности - это сознание своей особости и естественности своего государственного существования, на чем бы оно ни базировалось - на этничности, языке, религии, общем прошлом, географической общности или обособленности и так далее. Национальные идентичности не есть нечто раз и навсегда данное. Они могут зарождаться, исчезать и переинтерпретироваться ${ }^{11}$.

Согласно этому мнению, можно утверждать, что в русскоязычной драматургии Беларуси зародился и уже интерпретируется новый формат национальный идентичности, базирующийся на отмежевании от прошлого и настоящего, а также на идеализированных представлениях о будущем.

\section{Бескомпромиссный украинский взгляд на настоящее}

Если пьесы Н. Халезина и А. Курейчика носят автобиографический характер, то «Семейные сцены» Анны Яблонской и «Демоны» Натальи Ворожбит, авторов направления «новая драма», избравших социально острую проблематику, представляют собой попытку дать незалакированный портрет современности «со стороны».

Театральный критик Павел Руднев, как и многие другие, отмечает невостребованность этих драматургов на родине и их популярность в России ${ }^{12}$.

Наталья Ворожбит также подчеркивает в интервью свое стремление «отмежеваться» от национального театра: Наш театр медленно гниет, местами даже красиво. Мне не хочется его ругать. Этот театр находится в другом от меня измерении. Не хочу быть в нем поставлена. Я его созериаю, как исторические руины. (...) Я бы хотела видеть в театре хулиганские, провокачионнье, злье спектакли по современным пьесам с реакиией на нашу действительность ${ }^{13}$.

11 Б. Андерсон, Воображаемье сообщества. Размьиления об истоках и распространении начионализма, Москва 2001, с. 173.

12 Воспоминания коллег об Анне Яблонской, режим доступа: http://stihi.pro/672anna-yablonskaya-zhizn-i-gibel-vospominaniya-kolleg-stihi.html, дата доступа: 15.10. 2013.

13 Н. Ворожбит, Зрителю нужно делать больно, режим доступа: http://life.pravda. com.ua/interview/2011/05/13/78523/, дата доступа: 15.10.2013. 
Пьеса «Демоны» вполне отвечает этим требованиям. Современная украинская деревня Сорочинцы представляет своего рода аллегорию на всю не-городскую Украину. Здесь есть элементы гоголевской мистики, но они совершенно теряются на фоне беспробудного пьянства, одинакового и для украинской глубинки, и для российской, и для любой другой.

Мне, как драматургу, интересно разбираться, почему наш народ так много бухает. Я хочу, чтобы зритель увидел в театре себя пьющего на сцене. Жалкого, разрущающего себя, свою семью, свою страну. (...) Вокруг масса тем, многие из них напрямую тебя касаются, бери и пиши. Только не про ангелов ${ }^{14}$, - говорит автор пьесы.

Изображая неприкрыто отталкивающий быт современной деревни, Наталья Ворожбит, по собственному признанию, вступает в спор с теми, кто не хотят сльишать то, что каждый день сльишат в обычной жизни. Так в том то и дело, что мы себя не сльиши, других не сльишим. А со сцень все звучит иначе: острее, значительнее. Приобретает новые смьллль. Зрителя нужно воспитыьвать. Для этого нужно делать ему больно. Театр должен заставлять думать и сопереживать ${ }^{15}$.

Но излишняя прямолинейность, приближенность к неприглядной действительности не вызывает сопереживания, а скорее отталкивает.

Городские герои «Семейных сцен» Анны Яблонской также вызывают отторжение. Пожалуй, не будет преувеличением сказать, что пьеса фактически демонстрирует все нелицеприятные стороны современного города. Здесь нет возможности говорить о какой-либо самоидентификации, тем более - национальной. Герои «Семейных сцен»- это герои распада: личного, семейного, общественного.

Яблонская, - пишет Павел Руднев, - фиксирует тот нравственный тупик, в который погружена современная Россия. (Действительно, проблема ветеранов горячих точек гораздо более актуальна для России, нежели для Украины - А.Г.). Патологическая неустойчивость семьи, аутизм взросльх, неприкаянность и сиротство детей, дисфункиия общества, где опереться можно только на насилие как последнее проявление жизни ${ }^{16}$.

\footnotetext{
14 Там же.

15 Там же.

16 Павел Руднев, режим доступа: http://stihi.pro/672-anna-yablonskaya-zhizn-i-gibelvospominaniya-kolleg-stihi.html, дата доступа: 16.10.2013.
} 
По словам В. Хёсле,

всякий, кто хочет понять современный мир, едва ли достигнет своей цели, не поняв логики кризиса идентичности. (...) Самый глубокий и отчаянный кризис идентичности является результатом убеждения в том, что не существует никаких моральных норм. В этом случае кризис безысходен, потому что из него почти невозможно выкарабкаться: ведь человек не будет рассматривать свое состояние сознания как кризис, поскольку понятие «кризис» имеет нормативные коннотации, которые он отвергает; он не признается в ошибке, поскольку освободился от мысли об объективном различии между ошибкой и истиной ${ }^{17}$.

Именно такую беспросветную ситуацию представляют в своих пьесах украинские драматурги. В отличие от белорусских авторов, они не пытаются оттолкнуться от чего-то, «переинтерпритировать» личностную и национальную идентичность своих героев. Образно говоря, это «диагностирование кризиса», а не попытки его преодолеть. Впрочем, без верного диагноза невозможно и правильное лечение.

\author{
S T R E S Z C Z E N I E
}

\title{
SAMOIDENTYFIKACJA NARODOWA \\ WE WSPÓŁCZESNEJ ROSYJSKOJĘZYCZNEJ DRAMATURGII BIAŁORUSI I UKRAINY
}

Zwrócono uwagę na rosyjskojęzyczne utwory dramaturgiczne Białorusi i Ukrainy (N. Chalezin, A. Kurejczyk, N. Worożbit, A. Jabłońska). Pozwalają one wnioskować, że bohaterowie ich utworów cechuje kosmopolityzm, brak wyraźnej samoidentyfikacji narodowej, co wynika z odczucia wielokulturowości oraz heterogeniczności tradycji kulturowej. Jeśli w twórczości białoruskich autorów zarysowane jest kształtowanie się identyczności narodowej nowego formatu, to pisarze ukraińscy żyją wyłącznie problemami bieżącymi.

Słowa kluczowe: przestrzeń postsowiecka, dramaturgia, autor, bohater, samoświadomość narodowa.

17 В. Хёсле, Кризис индивидуальной и коллективной идентичности, «Вопросы философии», Москва 1994, № 10, с. 113. 
S U M M A R Y

\section{NATIONAL SELF-IDENTIFICATION \\ IN MODERN RUSSIAN LANGUAGE DRAMATURGY \\ IN BELARUS AND UKRAINE}

The knowledge of dramas written in Russian by Belarusian and Ukrainian playwrights (N. Khalezin, A. Kureytchic, N. Vorozbit, A. Yablonskaya) enables to conclude that the majority of heroes are cosmopolitan and lack national self-identification. The signs of polycultural, heterogeneous tradition are present. In the works of Belarusian authors new format of national identity based on conflicts with the country past and present appears whereas Ukrainian authors discuss current problems of the country.

Key words: Post-Soviet space, dramaturgy, author, hero, national identity. 